\title{
RA?EGA
}

O ESPACYO GEOGRAFICO EM ANÁLISE

\section{ANÁLISE MORFOESTRUTURAL DA BACIA DO RIBEIRÃO ÁGUA DAS ANTAS - PR}

\section{MORPHOSTRUCTURAL ANALYSIS OF THE RIBEIRÃO ÁGUA DAS ANTAS DRAINAGE BASIN- PR}

Recebido em: 04/08/2014

Karine Bueno Vargas

Programa de Pós-Graduação em Geografia Universidade Estadual de Maringá (UEM) Maringá, $P R$ e-mail: karibvargas@yahoo.com.br

Edison Fortes Departamento de Geografia Universidade Estadual de Maringá (UEM) Maringá, $P R$ e-mail: edison-fortes@hotmail.com

Eduardo Salamuni Departamento de Geologia Universidade Federal do Paraná (UFPR) Curitiba, $P R$ e-mail:salamuni@ufpr.br Aceito em: 04/05/2015

\section{Resumo}

A bacia hidrográfica do ribeirão Água das Antas localiza-se no centro norte do estado do Paraná, tendo seu maior domínio do município de Grandes Rios, na transição do Segundo para o Terceiro Planalto Paranaense. Está modelada sobre as litoestruturas das Formações Rio do Rasto, Pirambóia, Botucatu e Serra Geral da Bacia Sedimentar do Paraná. No presente artigo são identificadas e interpretadas as anomalias de drenagem na referida bacia, a partir da aplicação de índices morfométricos e de técnicas de sensoriamento remoto e geoprocessamento para a confecção de anomalias da área de estudo. As anomalias de drenagem correspondem a anormalidades ou irregularidades decorrentes principalmente de processos morfoestruturais e morfotectônicos. Os índices morfométricos utilizados, como fator de assimetria da bacia, fator de simetria topográfico transversal e relação declividade-extensão, apresentaram dados satisfatórios, com a identificação de alto índice de assimetrias na bacia. Por meio da fotointerpretação foram identificados curvaturas anômalas, segmentos retilíneos, erosões ativas, zona de abandono de drenagem, drenagens radiais e sub-radiais e tendência de migração do canal, as quais são consideradas anomalias. Devido à forte assimetria do canal, a bacia do ribeirão Água das Antas foi analisada à luz de zonas morfoestruturais, geradas pelo 
desnivelamento de blocos de falhas, sendo possível verificar a atuação da tectônica recente que afetou a rede de drenagem.

Palavras-chave: Anomalias de Drenagem, Análise Morfometrica, Morfoestruturas, Neotectônica.

\begin{abstract}
Água das Antas River Basin is located in central north state of Paraná, having its greater domain on Grandes Rios city, at the transition from the Second to Third Paranaense Plateau. It's modeled on Rio do Rasto, Pirambóia, Botucatu e Serra Geral Formations of Paraná Sedimentary Basin. In the present paper are identified and interpreted drainage anomalies in that catchment, from aplication of morphometric indexes, remote sensing tecnics and geoprocessing for making maps of annomalies from the study area. The drainage anomalies and asymmetries correspond to abnormalities or irregularities from morphoestructural e morphotectonical processes mainly. The morphometrical indexes used, as the factor of asymmetry of the basin, transverse topographic symmetry factor and slope length relationship showed satisfactory data, identifying high degree of asymmetry in the basin. Through photointerpretation were identified anomalous curvatures, straight segments, active erosion, abandonment of drainage area, drainage and sub-radial and radial migration trend channel which are considered anomalies. Due to the strong asymmetry of the channel, Água das Antas River catchment was analyzed in the light of morphostructural zones, generated by the difference of fault blocks being possible check the action of the recent tectonics affecting the drainage network.
\end{abstract}

Keywords: Drainage Anomalies, Morphometric Analysis, Morphostructures, Neotectonics.

\title{
1. INTRODUÇÃO
}

A geomorfologia estrutural é o ramo da geomorfologia consagrada à análise das relações estabelecidas entre o relevo da superfície da terra e as estruturas geológicas, tratando das formas de relevo cuja existência, aspecto ou geometria dependem diretamente das condições geológicas (PEULVAST; VANNEY, 2002).

As morfoestruturas correspondem à estrutura mórfica e geológica do terreno, geralmente referenciando-se a embasamentos estruturais (cristalinos e/ou sedimentares), ou seja, equivale a feições geomorfológicas correlacionadas exclusivamente a estrutura geológica, tais como bacias sedimentares, cadeias orogênicas e plataformas (GERASIMOV; MESCHERIKOV, 1968).

De acordo com Saadi (1998), a abordagem morfoestrutural focaliza o controle exercido sobre a morfologia pelo arcabouço litoestrutural, entendido como o conjunto 
de "elementos geológicos passivos", como, por exemplo, a natureza litotípica (rochas sedimentares, ígneas, metamórficas), o arranjo de camadas (dobradas, monoclinais, horizontais) e as rupturas crustais (falhas, zonas de cisalhamento). Todavia, para uma boa análise do relevo deve haver a inter-relação entre os fatos geomorfológicos e as ações geológicas e climáticas nele atuantes.

Segundo Christofoletti (1980), a bacia hidrográfica como unidade de análise tem um funcionamento sistêmico, o que facilita a análise dinâmica do conjunto de elementos e unidades que compõem o sistema e também permite indagar e averiguar as relações entre este sistema e o meio que está inserida.

Para Volkov et al. (1967), Ouchi (1985), Phillips; Schumm (1987); Schumm (1993) e Wescott (1993) a rede de drenagem é um dos elementos mais sensíveis às modificações tectônicas, posto que altera seu curso e adapta suas formas, além de apresentar padrões de acordo com as estruturas do modelado do relevo. De acordo com Schumm et al. (2000), cada padrão de drenagem apresenta um significado litoestrutural.

Entre as pesquisas sobre eventos tectônicos recentes está o emprego de técnicas de análise de parâmetros fluviais e morfométricos. Tendo como princípio de que os cursos de água, governados pela gravidade, reagem rapidamente a qualquer deformação na superfície do terreno, mesmo as mais tênues, tais técnicas podem, dessa forma, ser utilizadas para a identificação busca de anomalias que estejam condicionadas por deformações tectônicas (PENTEADO, 1978).

As abordagens estrutural e tectônica aplicadas à geomorfologia são ainda pouco exploradas no Brasil. Em regiões posicionadas em zonas de contatos litológicos e com acentuada energia de relevo, como é o caso da área de estudo, é possível utilizar o emprego de técnicas que atribuam a causas geológicas/estruturais a um melhor conhecimento sobre a morfogênese e evolução da paisagem.

No presente artigo, a bacia hidrográfica do ribeirão Água das Antas é analisada com o objetivo de compreender o seu significado morfoestrutural dentro da paisagem regional, com a finalidade de entender a associação de seus condicionantes geomorfológicos e geológicos. 


\section{ANÁLISE MORFOESTRUTURAL DA BACIA DO RIBEIRÃO ÁGUA DAS ANTAS - PR}

\section{MATERIAIS E MÉTODOS}

Para extrair as informações relativas à rede de drenagem foram utilizados métodos de fotointerpretação de fotografias aéreas do ITC-PR, na escala 1:25.000, utilizando-se do Manual Técnico de Geomorfologia IBGE (2009) para auxiliar na identificação das formas e padronização da legenda. As imagens foram analisadas por meio de estereoscópio de bolso e de espelho, possibilitando a transposição das informações para o papel. Empregaram-se os elementos de reconhecimento básicos para a leitura das fotos, tais como tonalidade, cor, forma, tamanho, padrão, textura, associação e sombra. Por fim, tais informações foram digitalizadas e georeferenciadas. O mesmo procedimento se deu para a confecção do mapa geológico, juntamente com aferição em campo. A edição gráfica dos mapas de localização, geologia e anomalias de drenagem para a geração do produto cartográfico final foi realizada em software Corel Draw X3.

A técnica denominada "Relação Declividade-Extensão (RDE)", também conhecida como "Índice de Hack", foi utilizada para a identificação de deformações crustais a partir de parâmetros morfométricos obtidos a partir do perfil longitudinal da drenagem. Realizou-se o cálculo por trecho e em sua totalidade, sendo utilizado o método descrito por Hack (1973), que mensura o índice RDE trecho (equação 1), calculado da seguinte forma:

$$
R D E=\left(\frac{D h}{D l}\right) L
$$

Onde, Dh é a diferença altimétrica entre dois pontos extremos de um segmento ao longo do curso d'água; DI é a projeção horizontal da extensão do referido segmento $\mathrm{Dh} / \mathrm{Dl}$ corresponde ao gradiente da drenagem naquele trecho; e $\mathrm{L}$ corresponde ao comprimento total do curso d'água a montante do ponto para o qual o índice RDE está sendo calculado.

O índice RDE total (equação 2) pode ser calculado da seguinte forma:

$$
\text { RDEtotal }=\left(\frac{D h}{D g . L}\right)
$$

Onde, $\mathrm{DH}$ é a diferença altimétrica entre a cota superior e inferior do canal, ou seja, a diferença entre a cota localizada a montante do rio e a cota localizada na sua foz; Lg L é o logaritmo natural da extensão total do curso d'água. 


\section{ANÁLISE MORFOESTRUTURAL DA BACIA DO RIBEIRÃO ÁGUA DAS ANTAS - PR}

Os setores anômalos são definidos a partir de limiares (equação 3), onde se considera:

$$
\text { Índice de gradiente RDE }=\left(\frac{\text { RDEtrecho }}{\text { RDEtotal }}\right)
$$

Os valores compreendidos entre os limiares 2 e 10 correspondem a anomalias de $2^{\underline{a}}$ ordem, já os valores superiores a 10 , anomalias de $1^{\underline{a}}$ ordem (SEEBER; GORNITZ, 1983 apud FUJITA, 2009).

Segundo Mackin (1948), uma determinada drenagem ou trechos da mesma poderão ser considerados em equilíbrio quando não se verifica assoreamento generalizado de um leito fluvial ou entalhe do talvegue, ocorrendo somente fluxo da carga sedimentar. Nesse caso, a curva apresenta uma típica forma côncava. Qualquer alteração no perfil leva a corrente a se ajustar na busca de um novo equilíbrio (MACKIN, 1948). Para Hack (1973), as curvas com menor concavidade indicariam condições de desequilíbrio e que podem ser indicativos de atividade tectônica recente. O tempo necessário para que a drenagem readquira o equilíbrio ou um quasi-equilibrium não pode ser definido.

De acordo com Etchebehere (2004), o índice RDE possibilita uma avaliação rápida, eficaz e de baixo custo acerca das hipóteses de ocorrência de neotectônica, servindo de parâmetro inicial de aplicação regional para áreas de interior cratônico.

Outro parâmetro morfométrico utilizado foi o Fator Assimetria da Bacia de Drenagem (FABD) (COX, 1994), no qual a assimetria de uma bacia reflete o componente de deslocamento lateral do seu rio principal, perpendicularmente à direção de seu eixo. É um modo de avaliar a existência de inclinações tectônicas em escala de uma bacia de drenagem e pode ser aplicado em áreas relativamente extensas e planas, onde sua migração é causada por processos fluviais internos e/ou forças deformacionais tectônicas (COX, 1994).

O Fator Assimetria da Bacia de Drenagem é definido na equação 4:

$$
F A B=100 \cdot\left(\frac{A r}{A t}\right)
$$

Onde, Ar é a medida da área de toda a porção direita da bacia no sentido jusante e At corresponde à medida da área total da bacia de drenagem. 


\section{ANÁLISE MORFOESTRUTURAL DA BACIA DO RIBEIRÃO ÁGUA DAS ANTAS - PR}

Quando o índice resultante possui valor próximo ou igual a 50, a bacia apresenta condições estáveis com relação a movimentação tectônica. Valores abaixo de 50 indicam provável basculamento da margem esquerda do canal, enquanto valores acima de 50 indicam provável basculamento da margem direita do canal (COX, 1994).

Adicionalmente, utilizou-se $\circ$ Fator de Simetria Topográfica Transversal (FSTT), proposto por Hare e Gardner (1985), o qual é baseado no fato de que a migração preferencial do canal caracteriza uma assimetria do perfil topográfico transversal ao canal. O FSTT é calculado de acordo com a (equação 5):

$$
T=\left(\frac{D a}{D d}\right)
$$

Onde, Da corresponde à distância da linha média do eixo da bacia de drenagem até a linha média do cinturão do meandro ativo e Dd é à distância da linha média da bacia ao divisor da bacia. Quando não há alteração do perfil topográfico, T é próximo a zero, enquanto a assimetria aumenta na medida em que os valores de $T$ se aproximam de 1.

Para extrair os lineamentos estruturais, analisou-se as fotografias áreas, juntamente com os dados SRTM, reamostrados com resolução $30 \mathrm{~m}$, obtidos do Projeto TOPODATA (VALERIANO, 2005). Esses dados foram importados para 0 software Global Mapper, que foram transferidos, por sua vez, para o software Spring versão 5. Com o auxílio do Spring, foram observadas imagens com padrões de cinza

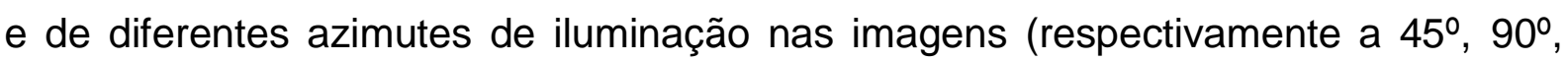
$180^{\circ}, 225^{\circ}, 270^{\circ}$ e $315^{\circ}$ ), com ângulo de inclinação de $45^{\circ}$ para que áreas sombreadas pudessem ser melhor observadas e aferidas, sendo extraído manualmente os lineamentos. Após a extração e vetorização dos lineamentos, foram produzidos diagramas de rosetas, proporcionando resultados de frequência absoluta e comprimento absoluto dos lineamentos. 


\section{ANÁLISE MORFOESTRUTURAL DA BACIA DO RIBEIRÃO ÁGUA DAS ANTAS - PR}

\section{RESULTADOS E DISCUSSÕES}

A bacia hidrográfica do ribeirão Água das Antas está localizada no centronorte do Estado do Paraná, tendo seu maior domínio no distrito de Ribeirão Bonito, pertencente ao município de Grandes Rios (Figura 1). A bacia encontra-se inserida na transição entre o Segundo e o Terceiro Planalto Paranaense (MAACK, 1968), numa área de bordas planálticas, as quais correspondem a um segmento da Serra Geral, que se estende desde o estado do Rio Grande do Sul até o estado de São Paulo como uma importante feição orográfica regional. $\mathrm{Na}$ área em estudo ela recebe denominações regionais, como Serra do Cadeado, Serra da Boa Esperança e/ou Serra da Caneleira.

O ribeirão Água das Antas é afluente do rio Alonzo, o qual é tributário do rio Ivaí, pertencente à bacia do rio Paraná. O ribeirão ocupa uma área de $42,65 \mathrm{~km}^{2}$, dispondo-se no sentido NW-SE paralelamente aos alinhamentos dos diques de diabásio, que constituem as principais estruturas que influenciaram na estruturação da bacia.

\section{Localização da Bacia do Ribeirão Água das Antas}
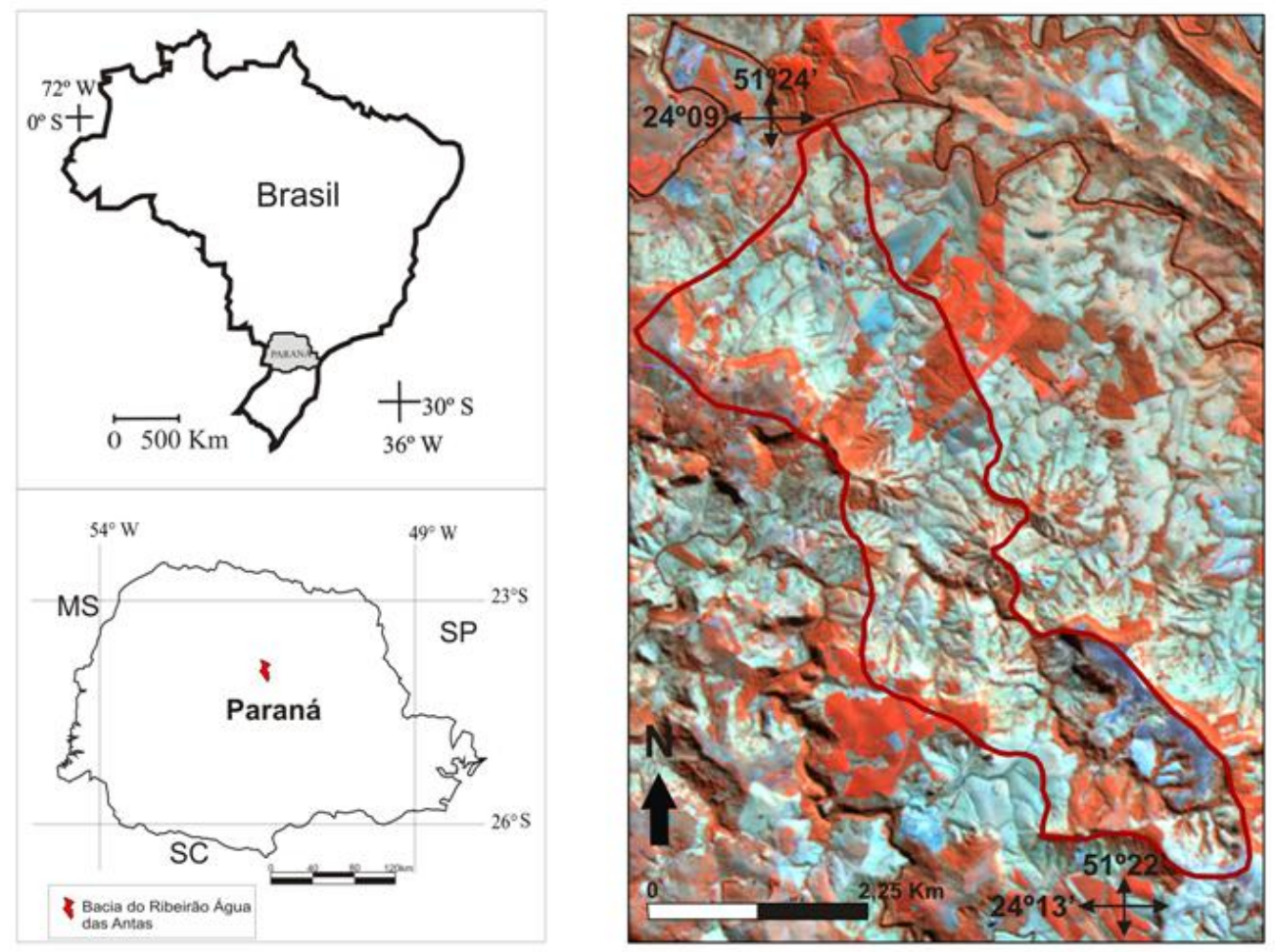

Figura 1: Localização da bacia do ribeirão Água das Antas, com delimitação da bacia de drenagem sobre imagem multiespectral do satélite Landsat 5. 
A bacia do ribeirão Água das Antas apresenta densidade de drenagem variável conforme a margem considerada, evidenciando-se significativamente superior junto aos afluentes da sua margem esquerda, principalmente do terço superior até a foz. Essa situação inverte-se em direção às cabeceiras de drenagem. Possui uma sinuosidade mista, com alto índice de angularidade e paralelismo, e uma tropia multidirecional com forte assimetria. O padrão de drenagem possui suas características geométricas com tendência ao padrão sub-dendrítico, mas também radial subsidiariamente. Em ambos os casos a declividade é uma fato controlador das morfoestruturas.

Observa-se que a curva disposta no perfil longitudinal da bacia do ribeirão Água das Antas (Figura 2) apresenta geometria mais ou menos afeiçoada a uma equação logarítmica, verificando-seapresentando pequenas quebras ou rupturas na linha de declividade. Essas rupturas devem representar processos que estão alterando o equilíbrio do curso d'água nos setores onde ocorrem. Geralmente, tais desequilíbrios estão ligados à confluências de tributários, heterogeneidade do substrato rochoso ou, ainda, a processos de deformação crustal. O canal apresenta uma significativa mudança de altitude ao longo do seu percurso, onde a nascente posiciona-se na cota dos $700 \mathrm{~m}$ de altitude, chegando a atingir quase $400 \mathrm{~m}$ de altitude em sua foz, onde deságua no rio Alonzo.

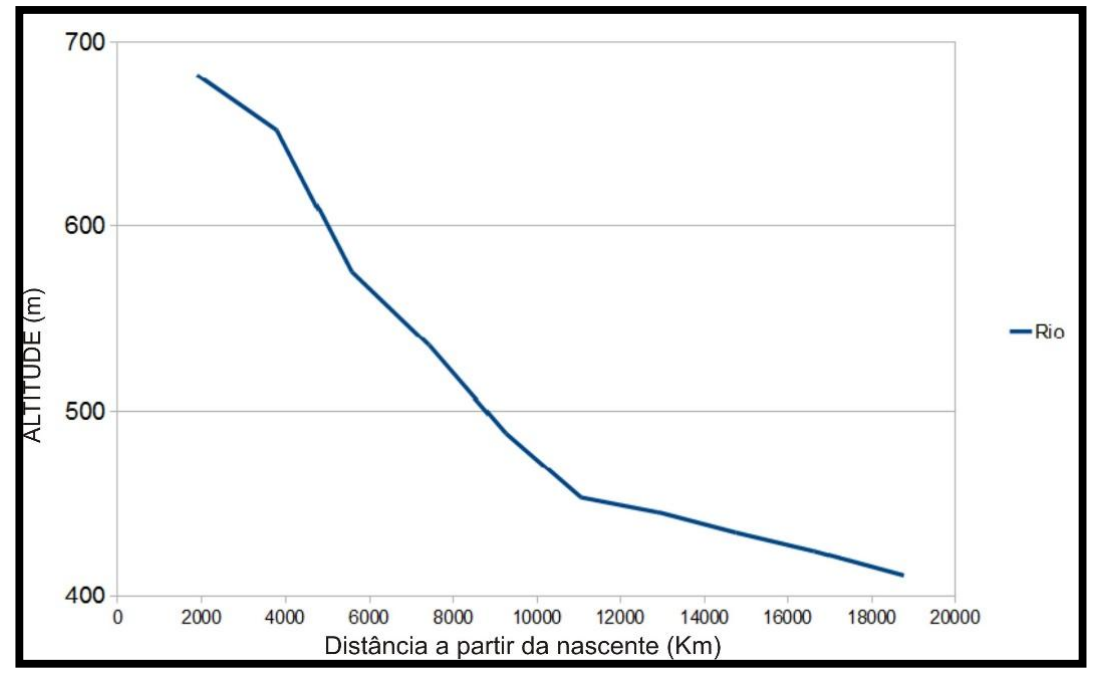

Figura 2: Perfil longitudinal do ribeirão Água das Antas.

A densidade de drenagem é um fator indicativo do grau de desenvolvimento do sistema hidrográfico de uma bacia. A bacia do ribeirão Água das Antas possui um 
formato alongado que facilita o seu escoamento superficial. Hierarquicamente essa bacia corresponde a uma drenagem de $4^{\circ}$ ordem, segundo o método de Strahler (1952), o que demonstra que a rede de drenagem possui uma considerável ramificação e possui uma forte densidade de canais. Outra informação obtida com a análise da rede de drenagem é que canais de primeira e segunda ordem são predominantes na bacia.

$\mathrm{Na}$ Tabela 1 estão inseridos os valores obtidos pelas análises da Assimetria da Bacia de Drenagem (FABD) e o Fator de Simetria Topográfico Transversal (FSTT), além de outros índices morfométricos.

Tabela 1: Dados morfométricos da bacia do ribeirão Água das Antas.

\begin{tabular}{l|c|l|l|l|l|l}
\hline Drenagem & Extensão(Km) & Cota Cab. & Cota foz & Amplitude & FABD & FSTT \\
\hline $\begin{array}{l}\text { Ribeirão } \\
\text { Água das } \\
\text { Antas }\end{array}$ & 18,76 & 682,96 & 406,95 & 276,01 & 36 & 0,54 \\
\hline
\end{tabular}

A bacia do ribeirão Água das Antas possui o perfil do canal sobre litologias pelíticas e psamíticas da Formação Rio do Rasto e, ao contrário do que se esperava, esse litotipo apresentou índices de RDE TOTAL superiores a 28 (Tabela 2 e Figura 4), indicando altos índices de anomalias, bem como fortes desajustes no perfil longitudinal. Vários trechos indicaram valores de RDE acima de 2 (Tabela 2), que resultam em anomalias de segunda ordem, apresentando desajustes com a linha de melhor ajuste.

Tabela 2: Variáveis morfométricas para a aplicação do índice RDE.

\begin{tabular}{r|r|l|r|r|r|r|r|r}
\hline Trecho & $\begin{array}{l}\text { Cota } \\
\text { superior }\end{array}$ & $\begin{array}{l}\text { Cota } \\
\text { inferior }\end{array}$ & $\begin{array}{l}\text { Diferença } \\
\text { altimétrica }\end{array}$ & $\begin{array}{l}\text { Ext. } \\
\text { trecho }\end{array}$ & $\begin{array}{l}\text { Ext. } \\
\text { Total }\end{array}$ & Declividade & $\begin{array}{l}\text { RDE } \\
\text { trecho }\end{array}$ & $\begin{array}{l}\text { RDEtrecho/ } \\
\text { RDEtotal }\end{array}$ \\
\hline 01 & 682,96 & 655,66 & 27,3 & 1873,8 & 1873,8 & 0,01457 & 27,3 & 0,97 \\
\hline 02 & 652,92 & 576,65 & 76,27 & 1917,26 & 3791,06 & 0,03978 & 150,82 & 5,38 \\
\hline 03 & 575,01 & 537,07 & 37,94 & 1781,56 & 5572,62 & 0,02129 & 118,67 & 4,23 \\
\hline 04 & 535,31 & 490,18 & 45,13 & 1860,08 & 7432,7 & 0,2426 & 180,34 & 6,43 \\
\hline 05 & 488,62 & 454,01 & 34,61 & 1818,41 & 9251,12 & 0,01903 & 176,05 & 6,28 \\
\hline 06 & 453,42 & 446,94 & 6,48 & 1805,07 & 11056,19 & 0,00359 & 39,67 & 1,41 \\
\hline 07 & 445,25 & 434,22 & 11,03 & 1833,55 & 12889,74 & 0,00602 & 77,55 & 2,76 \\
\hline 08 & 434,2 & 424,71 & 9,49 & 1866,03 & 14755,76 & 0,00509 & 75,05 & 2,68 \\
\hline 09 & 424,48 & 411,95 & 12,53 & 1874,72 & 16630,48 & 0,00668 & 111,11 & 3,96 \\
\hline 10 & 411,82 & 406,95 & 4,86 & 2131,84 & 18762,32 & 0,00228 & 42,81 & 1,53 \\
\hline
\end{tabular}

Fonte: Couto (2011). 


\section{ANÁLISE MORFOESTRUTURAL DA BACIA DO RIBEIRÃO ÁGUA DAS ANTAS - PR}

Destaca-se que a bacia possui outros litotipos além da Formação Rio do Rasto, tais como as formações Pirambóia, Botucatu e Serra Geral, que se localizam nas áreas mais elevadas topograficamente, correspondentes a escarpas e patamares. Porém, o embasamento da bacia é predominantemente composto por rochas da Formação Rio do Rasto (Figura 3).

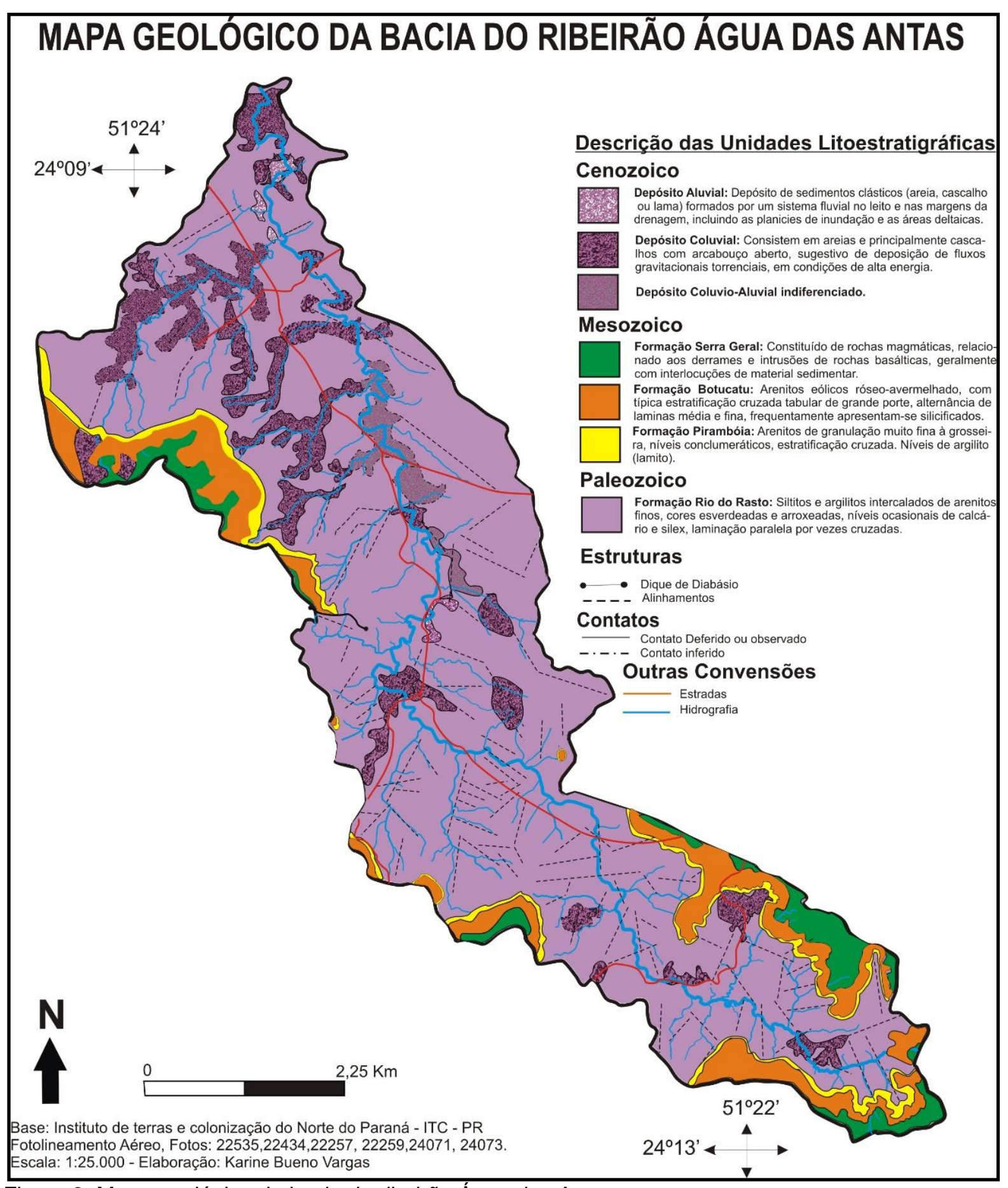

Figura 3: Mapa geológico da bacia do ribeirão Água das Antas. 
A partir do gráfico de RDE (Figura 4) observou-se, além da tendência geral de diminuição dos valores de RDE rumo à nascente do ribeirão Água das Antas, a presença de três áreas anômalas significativas, as quais são visíveis pelas mudanças bruscas no gradiente do canal:

1. Primeira anomalia $(A)$ - localiza-se a cerca de $4 \mathrm{Km}$ da nascente do ribeirão Água das Antas, abrangendo uma área média de $1 \mathrm{~km}^{2}$, e caracteriza-se por um soerguimento da área, pois a linha de melhor ajuste encontra-se abaixo do perfil longitudinal, havendo um aumento relativo do RDE, seguido de uma diminuição do valor.

2. Segunda anomalia (B) - encontra-se, aproximadamente, a $8 \mathrm{~km}$ da nascente do ribeirão, verificando-se um aumento do índice RDE onde é representado no gráfico pela elevação da linha RDE, seguida de um abatimento brusco da área onde é representado no gráfico pela queda da linha RDE e pela linha de melhor ajuste que está acima do perfil longitudinal, caracterizando uma área de alternância de condições estruturais e que sugere uma zona limítrofe de blocos.

3. Terceira anomalia (C) - situada, aproximadamente, a $14 \mathrm{~km}$ da nascente, com início no ponto da queda brusca do índice RDE associado à segunda anomalia (B). No local o índice aumenta gradativamente, se estabiliza até a foz do ribeirão, havendo uma interface entre o abatimento e soerguimento da área.

O valor do FABD do ribeirão Água das Antas resultou em 36, indicando uma provável movimentação da margem esquerda para a margem direita. Mesmo o valor do índice tendo sido pouco significativo, quando se analisa a bacia por trechos verifica-se que ocorrem fortes assimetrias na bacia. Infere-se que o índice 36 pode estar associado às alternâncias de deslocamento do canal ao longo da bacia, refletindo um estado médio do comportamento estrutural.

O valor de Fator Simetria Topográfica Transversal (FSTT) total foi 0,54 indicando um basculamento intermediário, devido à baixa migração do canal, fato que corrobora com o valor do Fator de Assimetria da Bacia (FAB).

Os dados morfométricos mostraram que a área possui anomalias de drenagem, localizadas ao longo de todo o canal. A partir da fotointerpretação foi possível mapear tais anomalias, interpretando-se que as áreas assimétricas mapeadas coincidem com as alterações do índice RDE. 


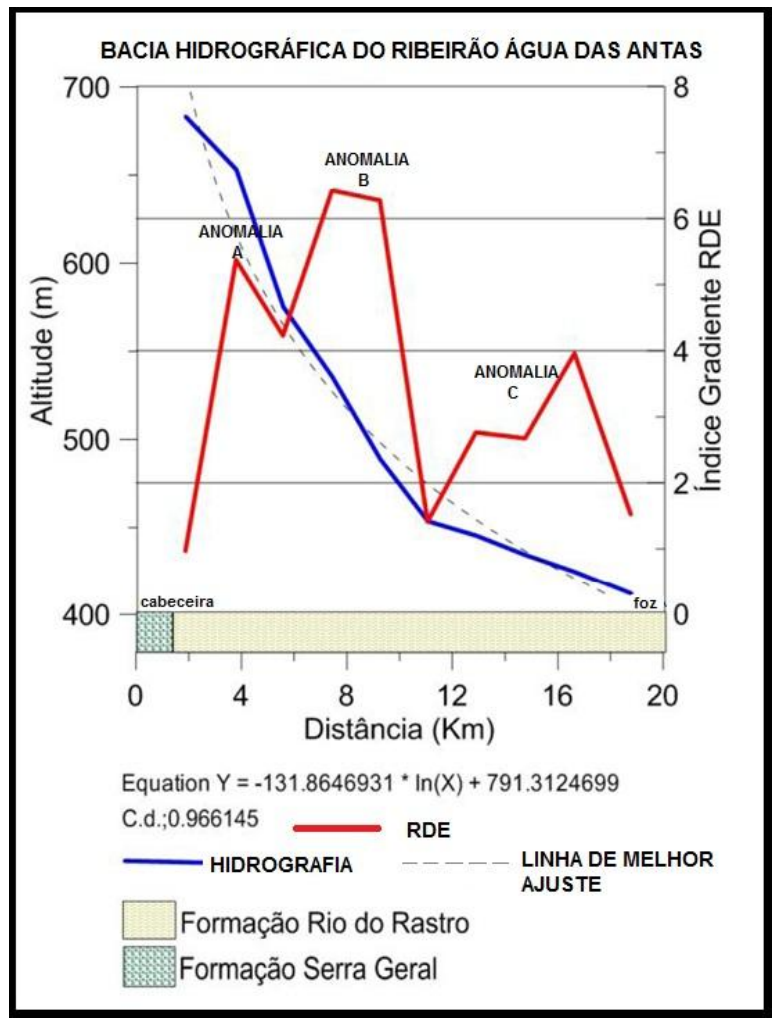

Figura 4: Distribuição de valores RDE (Relação Declividade-Extensão) ao longo do perfil longitudinal do ribeirão Água das Antas, evidenciando as três principais anomalias. Modificado de Couto (2011).

A figura 5 mostra o mapa das anomalias de drenagem do ribeirão Água das Antas e suas principais unidades anômalas na bacia. Ali foram demarcadas as zonas morfoestruturais, segmentos retilíneos, erosões ativas, curvaturas anômalas, zona de abandono de drenagem, drenagens radiais e direção de tendência de migração do canal.

No mapa de anomalias (Figura 5) foram encontradas ao todo 23 curvas anômalas, concentradas no baixo e médio curso, e, no entanto, elas ocorreram em sua maioria no canal principal do ribeirão. Para Howard (1967), feições desse tipo estão relacionadas ao controle estrutural e podem ser indicativos de movimentação tectônica recente ou inversão de relevo. Curvas e voltas podem ser consideradas anômalas quando estão transversais ao canal, provocando desvios ao redor das feições ou bloqueio nos tributários que são refletidos para uma drenagem vizinha ocorrendo o abandono de canais.

Foram também reconhecidos ao longo de toda a bacia um total de 48 segmentos retilíneos. Esses segmentos representam um importante indicador de controle estrutural, os quais podem estar associados às zonas de fraturas. Segundo 
Howard (1967), os segmentos retilíneos são mais comuns em canais retos e extensos, os quais não apresentam padrão retangular e treliçamento, estando associados geralmente a fraturas, falhas, veios, diques e juntas.

Com base nos parâmetros morfológicos, estruturais, hidrográficos e morfométricos, foi possível propor quatro zonas morfoestruturais (Figura 5). Essas unidades têm como principal parâmetro de análise os sistemas hidrográficos que compõem a bacia do ribeirão Água das Antas.

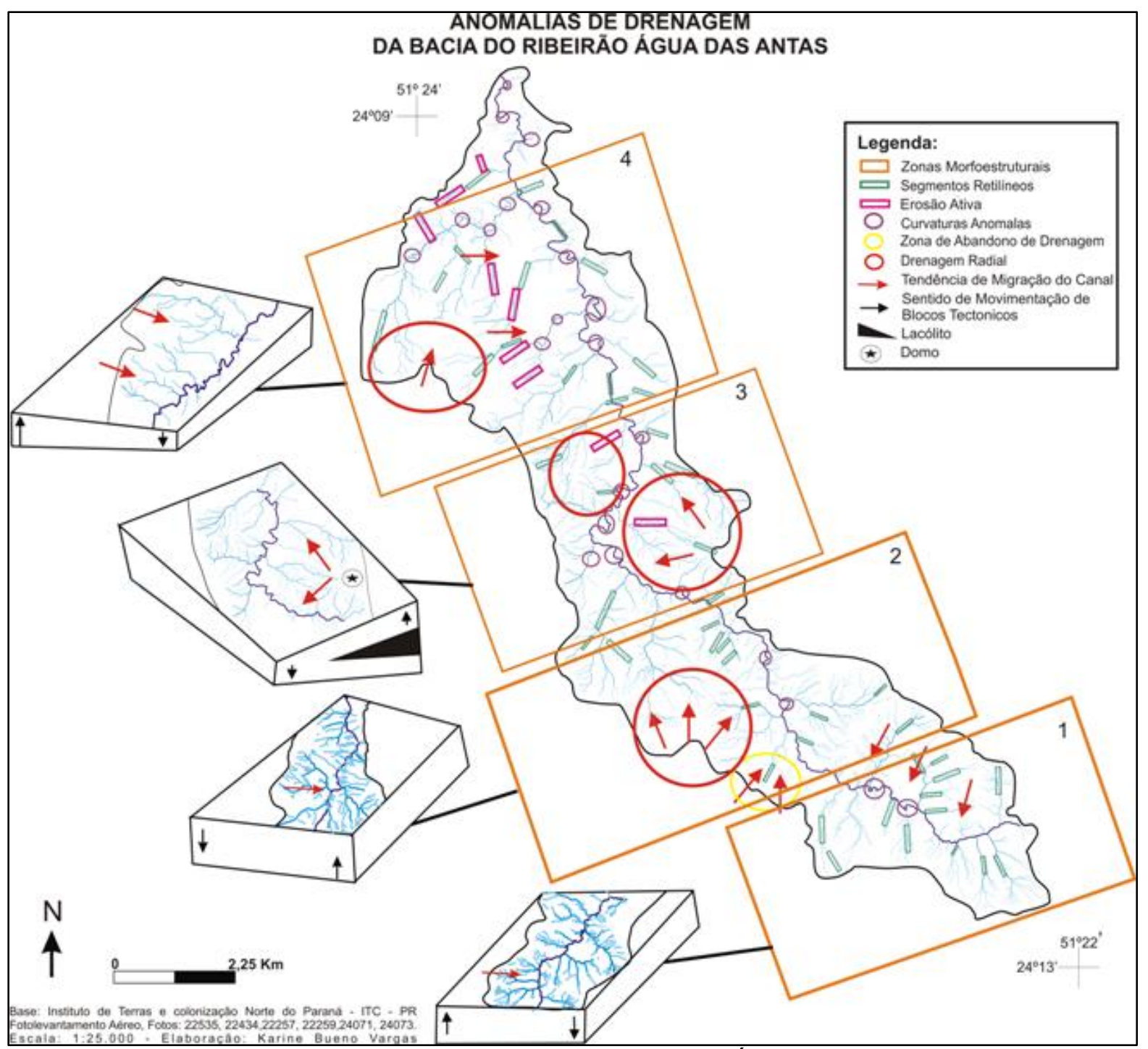

Figura 05: Mapa de anomalias de drenagem da bacia do ribeirão Água das Antas.

A primeira zona morfoestrutural (1), localizada na parte montante, junto às cabeceiras de drenagem do ribeirão Água das Antas, é marcada por condições mais simétricas que as demais zonas. Contudo, no alto curso dessa zona morfoestrutural 
o canal principal apresenta forte assimetria, com drenagens de primeira ordem significativamente mais extensas junto à margem direita e drenagens menores na margem esquerda. O desvio brusco para a esquerda do canal evidencia importante controle estrutural por falhas do canal (Figura 5).

A zona morfoestrutural 2, situada no terço montante da bacia, apresenta forte assimetria, com inflexão do canal para a margem esquerda. O padrão semi-radial da drenagem correspondente aos afluentes da margem esquerda do ribeirão Água das Antas, demonstra que esse rio executa um desvio de estrutura (Figura 5).

Outro importante elemento geomorfológico presente nessa zona morfoestrutural é uma área de captura ou abandono de drenagem (Figura 5), observada em fotos aéreas, mas ainda não bem esclarecida, que mostra um interflúvio muito rebaixado em que os divisores de água são difíceis de determinar. Situado junto ao interflúvio da margem esquerda, esse setor sugere que o ribeirão Água das Antas apresentava outro afluente pela sua margem esquerda, e em virtude de soerguimento suave, provocou o abandono desse afluente, que passou a ser capturado pelo rio Branco, que constitui importante afluente do rio Ivaí.

Outra possibilidade é que o terço superior do ribeirão Água das Antas, poderia pertencer ao rio Branco, na bacia vizinha ao ribeirão nesse trecho, tendo sido capturado posteriormente. De qualquer forma esse processo indicaria soerguimento pequeno do interflúvio, mas suficiente para causar desajustes no sistema fluvial.

A Zona Morfoestrural 3 (Figura 5), localizada no médio curso da bacia mostra novamente mudança do curso do ribeirão Água das Antas, quando no seu fluxo para jusante sofre inflexão para a margem esquerda, desviando aparentemente de estruturas localizadas junto ao interflúvio da margem direita e de outra menor na margem esquerda e mais a jusante, antes do ribeirão entrar na Zona Morfoestrutural 4. Todas as estruturas morfológicas em formato de domos ou morros concavos apresentam drenagens radiais ou semi-radiais, sendo a mais importante aquela localizada junto a margem direita.

A Zona morfoestrutural 4 (Figura 5) corresponde a zona mais a jusante, próximo a foz do ribeirão Água das Antas. Essa é a área com os interflúvios mais distantes, com cerca de $4 \mathrm{~km}$ na margem esquerda. A forte assimetria do vale é 


\section{ANÁLISE MORFOESTRUTURAL DA BACIA DO RIBEIRÃO ÁGUA DAS ANTAS - PR}

marcada pelo deslocamento do canal principal em direção a margem direita, contornando as escarpas adaptadas de falha.

As alternâncias sucessivas de deslocamentos de segmentos do canal ao longo do seu curso impõem ao sistema fortes assimetrias, corroborada pelos índices morfométricos de RDE, FABD e FSTT. Sugere-se a presença de estruturas dômicas, com drenagens radiais e semi-radiais nesse processo de deslocamento, as quais estão associadas aos derrames basálticos e à intrusão de corpos lacolíticos durante - Mesozóico. A presença de falhas normais distensivas ao longo das drenagens de primeira ordem, junto aos domos, e entulhadas de blocos e cascalhos permite inferir condições recentes, possivelmente quaternárias, no processo de deslocamento do ribeirão Água das Antas e seus afluentes.

O traçado dos lineamentos indica forte relação com o sistema hidrográfico da bacia, com predomínio de lineamentos de direções N-S e NE (Figura 6), com destaque para o primeiro, sugestivo de atividade tectônica recente. Para Santos et al. 2008, estes trends pertencem aos lineamentos estruturais principais do rio Ivaí em seu curso inferior. Já Salamuni et al., (2004), relata que os lineamentos direcionados N-S na Bacia Sedimentar de Curitiba são expressivos nos depósitos quaternários, podendo ter sido formados no último pulso tectônico desta bacia. De encontro, nesta perspectiva Saadi (1993), destaca que os trends de direção N/S correspondem a movimentações quaternárias na porção central da Bacia do Paraná, e que os esforços tectônicos podem ser transmitidos mesmo em regiões intraplacas, como é o caso da área em estudo.

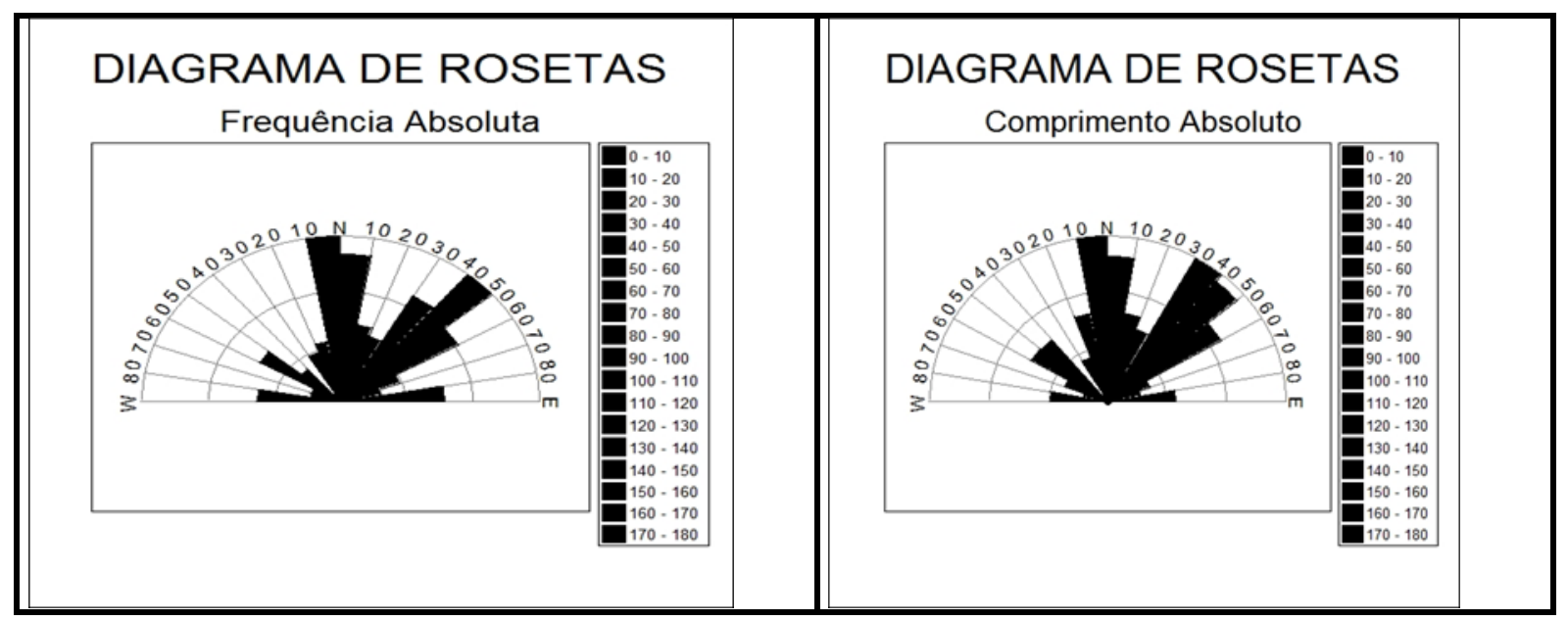

Figura 6: Gráficos de Roseta - Frequência Absoluta/Comprimento Absoluto dos Lineamentos da Bacia do Ribeirão Água das Antas. 


\section{ANÁLISE MORFOESTRUTURAL DA BACIA DO RIBEIRÃO ÁGUA DAS ANTAS - PR}

Para Strugale et al., (2007), a região apresenta alterações geométricas em função do posicionamento das mesmas em relação ao eixo do Arco de Ponta Grossa e os alinhamentos estruturais-magnéticos Rio Alonzo e São Jerônimo Curiúva. Esta diferença geométrica pode relacionar-se a um componente direcional mais proeminente em comparação ás zonas de falhas situadas nos referidos alinhamentos, as quais exibiriam um registro de movimentos gravitacionais nas falhas. Em campo as medidas de falhas e estrias nas escarpas, indicam movimentos normais com componentes direcionais, o que indica os processos de basculamento de blocos, conforme demonstrado nos parâmetros morfométricos.

É possível inferir que os basculamentos, com migração de canal e formação de falhas extensionais resultem em deformações na superfície, impondo processos de erosão acelerada ao longo das vertentes.

As bordas erosivas presentes principalmente nas áreas de escarpas e patamares dissecados sugerem retomadas erosivas pelo canal do ribeirão Água das Antas, com rebaixamento do talvegue, promovidas por provável atividade neotectônica.

\section{CONSIDERAÇÕES FINAIS}

O canal principal do ribeirão Água das Antas percorre, em sua totalidade, a Formação Rio do Rasto, intensificando os processos denudacionais da bacia e transportando os sedimentos para as áreas adjacentes, já que está litologia é bastante friável. Esse material transportado corresponde a depósitos quaternários de colúvios e alúvios, onde geomorfologicamente representam os modelados de deposição tais como as rampas coluviais e as planícies aluviais. Os depósitos apresentam-se como alvéolos ao longo dos canais, sendo retrabalhados pela intensa rede de drenagem da bacia, predominando o transporte de sedimentos na forma de colúvios.

A análise da rede de drenagem para identificação das influências morfoestruturais na evolução das bordas planálticas da bacia hidrográfica do ribeirão Água das Antas apresentou resultados satisfatórios. A bacia foi analisada por zonas morfoestruturais devido às alternâncias de blocos tectônicos na área. 
Verificou-se, portanto, que as anomalias indicadas através dos parâmetros morfométricos utilizados na bacia do ribeirão Água das Antas, são possivelmente resultantes de pulsos tectônicos e que representam forte controle estrutural, o que evidencia a atuação de processos neotectônicos sobre a bacia, ou seja, as atividades tectônicas tiveram papel ativo, se não determinantes, na evolução da bacia do ribeirão Água das Antas juntamente com os processos erosivos.

\section{REFERÊNCIAS}

CHRISTOFOLETTI, A. Geomorfologia. São Paulo: Edgard Blücher, 1980. 174 p.

COX, R. T. Analysis of Drainage-basin symmetry as a rapid technique to identify areas of possible Quaternary tilt-block tectonics: An example from the Mississipi Embayment. Geological Society of American Bulletin, University of Coluymbia, Missouri, v. 106, p 571-581, 1994.

COUTO, E. V. Influência morfotectônica e morfoestrutural na evolução das drenagens nas bordas planálticas do alto Ivaí - rio Alonzo - Sul do Brasil. Dissertação (Mestrado em Geografia). Universidade Estadual de Maringá. Maringá, 2011.

ETCHEBEHERE, M. L. C.; SAAD, A. R.; PERINOTTO, J. A. J.; FULFARO, V. J. Aplicação do Índice "Relação Declividade-Extensão - RDE" na Bacia do Rio do Peixe (SP) para detecção de deformações neotectônicas. Revista do Instituto de Geociências - USP - Série Científica, São Paulo, v. 4, n. 2, p. 43-56, 2004.

FUJITA, R. H. O perfil longitudinal do rio Ivaí e sua relação com a dinâmica de fluxos. 2009. Dissertação (Mestrado em Geografia). Universidade Estadual de Maringá, Maringá.

GERASIMOV, I.P.; MESCHERIKOV, J.A. Morphostructure. The Encyclopedia of Geomorphology. Encyclopedia of Earth Sciences. v. III, Fairbridge, R.W. ed., Dowden, Hulchinson \& Koss Inc., Pennsylvania. p. 731-732.1968.

HACK, J. T. Stream-profile analysis and stream-gradient index. U.S. Geol. Survey, Journal Research, 1(4): 1973, p. 421-429. 
HARE, P. W.; GARDNER, I. W. Geomorphic indicators of vertical neotectonism along converging plate margins. Nicoya Peninsula, Costa Rica. In: Morisawa, M.; HACK, J. T. (eds.) Tectonic Geomorphology. Procedings 15th. Annual Binghamton Geomorphology Simp,1985.

HOWARD, A. D. Drainage analysis in geologic interpretation: summation. Bulletin American Association of Petroleum Geologist, 51(11): 2246-2259, 1967.

INSTITUTO BRASILEIRO DE GEOGRAFIA E ESTATÍSTICA - IBGE. Manual técnico de geomorfologia. Coordenação de Recursos Naturais e Estudos Ambientais. Rio de Janeiro: IBGE, 2ํed., 2009. 182 p.

MAACK, R. Geografia Física do Paraná. Curitiba: José Olimpio, 1968.

MACKIN, J. H. Concept of the graded river. Geological Society of America Bulletin, v. 59, p. 463-512, 1948.

OUCHI, S. Response of alluvial rivers to slow active tectonic movement. Geological Society of American Bulletin. v. 96, p. 504-15, 1985.

PENTEADO, M. M. Fundamentos de Geomorfologia. Rio de Janeiro: IBGE, $1978.154 \mathrm{p}$.

PEULVAST, J.; VANNEY, J. Géomorphologie structurale: terre, corps planétaires solides. Tome 1: Relief et structure. Co-édition Gordon and Breach Science Publishers, Édi t ions du BRGM, Or léans, et Société géologique de France, Paris, 2002.

PHILLIPS, L. F.; SCHUMM, S. A. Effect of regional slope on drainage networks. Geology. v. 15, p. 813-816, 1987.

SAADI, A. Neotectônica da plataforma brasileira: esboço e interpretação preliminares. Geonomos, IGC/UFMG, Belo Horizonte. vol I, n 1, p.1-15, 1993.

SAADI, A. Modelos morfogenéticos e tectônica global: reflexões conciliatórias. Geonomos, ICG/UFMG, Belo Horizonte. n 6, p. 55-63, 1998.

SALAMUNI, E.; EBERT H. D.; HASUI Y. MORFOTECTÔNICA DA BACIA SEDIMENTAR DE CURITIBA. Revista Brasileira de Geociências. vol. 34 , p 469478, 2004. 
SANTOS, M.L.; STEVAUX, J.C.; GASPARETTO, N.V.L.; SOUZA FILHO, E. E. Geologia e geomorfologia da planície aluvial do rio Ivaí em seu curso inferior. Revista Brasileira de Geomorfologia, v.9, n.1, p. 23 - 34, 2008.

SCHUMM, S. A. River response to baselevel change: Implications for sequence stratigraphy. Journal of Geology. v. 101, p. 279-294, 1993.

SCHUMM, S. A.; DUMONT, J. F.; HOLBROOK, J. M. Active tectonics and alluvial Rivers. Cambridge: Cambridge University Press, 2000.

STRAHLER, A. N. Hypsometric (area-altitude) analysis of erosional topography. Geological Society of America Bulletin. 63, p.1117-1142, 1952.

STRUGALE, M.; ROSTIROLLA, S.P.; MANCINI, F.; PORTELA FILHO, C.V.; FERREIRA, F.J.F.; FREITAS, R.C. Structural framework and Mesozoic-Cenozoic evolution of Ponta Grossa Arch, Paraná basin, southern Brazil. Journal of South American Earth Sciences, 24: 203- 227, 2007.

VALERIANO, M. M. Modelo digital de variáveis morfométricas com dados SRTM para o território nacional: projeto TOPODATA. In: XII SIMPÓSIO BRASILEIRO DE SENSORIAMENTO REMOTO, 2005, Goiânia, GO. Anais. São José dos Campos: INPE, 2005. Artigos, p. 3595-3602. Disponível: http://marte.dpi.inpe.br/col/tid.inpe.br/sbsr/2004/10.29.11.41/doc/3595.pdf. Acesso em: 26/10/12.

VOLKOV, N. G.; SOKOLOVSKY, I. L.; SUBBOTIN, A. I. Effect of recent crustal movements on the shape of longitudinal profiles and water levels in rivers. In: INTERNATIONAL SYMPOSIUM ON RIVER MECHANICS. Proceedings. International Union of Geodesy and Geophysics.Bern. p. 105-116, 1967.

WESCOTT, W. A. Geomorphic thresholds and complex response of fluvial systems Some implications for sequence stratigraphy. AAPG Bulletin, v. 77, n. 7, 1993. p. 1208-1218. 